\title{
Management of Oral Iron Chelator Deferasirox for Transfusion-Dependent Patients with Hematological Disorders: 2-Year Experience at a Single Institution in Japan
}

\author{
Michihide Tokuhira, Morihiko Sagawa, Reiko Watanabe, Tomoe Nemoto, Takeshi Tomikawa, \\ Shigehisa Mori, Masahiro Kizaki \\ Department of Hematology, Saitama Medical Center, Saitama Medical University, Kawagoe, Japan. \\ Email: tokuhira@saitama-med.ac.jp
}

Received February $3^{\text {rh }}$, 2011; revised March 16 ${ }^{\text {th }}$, 2011; accepted April 11 ${ }^{\text {th }}, 2011$.

\begin{abstract}
Introduction: Deferasirox is an oral iron chelator, approved worldwide for the treatment of chronic iron overload due to transfusion. Deferasirox was permitted two years ago in Japan, but there is little known regarding its efficacy and tolerability in clinical practice. Methods: We conducted a retrospective study of 18 patients with transfusion-dependent anemias treated by deferasirox at our institution. The starting dose was individualized and ranged from 6.4 to 26.3 $\mathrm{mg} / \mathrm{kg} /$ day. Routine clinical laboratory data were followed, and serum ferritin was assessed every 4 weeks. Results: The mean serum ferritin level of 18 patients at the time of deferasirox induction was $3162 \mathrm{ng} / \mathrm{ml}$. 10 of 18 patients could sustain deferasirox treatment for at least 6 months, at an average maintenance dose of $10.8 \mathrm{mg} / \mathrm{kg} /$ day. Serum ferritin reduction was observed in 4 patients, at doses less than $20 \mathrm{mg} / \mathrm{kg} /$ day. Eighty-nine percent of the patients had adverse events and 13 of them in all ultimately discontinued. Myelodysplastic syndrome (MDS) patients showed poor tolerability. Severe infections of grade 3 or more were documented in 6 patients, and 2 of them were fatal. Conclusions: The potential for beneficial iron chelation of deferasirox at less than the recommended 20- $\mathrm{mg} / \mathrm{kg}$ dose was demonstrated. On the contrary, poor tolerability was documented, with adverse events such as severe infections, especially in MDS patients. Although it was not clearly demonstrated that deferasirox was responsible for impaired immunity, careful watching is required to administrate deferasirox.
\end{abstract}

Keywords: Omponent, Formatting, Style, Styling, Insert

\section{Introduction}

Patients with hematological disorders such as myelodysplastic syndrome (MDS) and aplastic anemia (AA) frequently require ongoing red blood cell (RBC) transfusion support. The frequent transfusions result in iron overload, leading to increased non-transferrin-bound iron, which generates toxic oxygen free-radicals and damage to multiple organs such as skin, liver, heart, pancreas, and other organs [1-3]. As previous observations have demonstrated that severe iron overload is associated with increased morbidity and mortality, iron chelation therapy is important [4-6]. Deferoxamine (DFO) is a chelation medication that has been effective at achieving a negative iron balance when applied to patients with transfusion-related iron overload $[7,8]$. On the other hand, DFO requires intravenous injection or subcutaneous administration every day, resulting in impaired quality of life. By contrast, deferasirox is a once-daily, oral iron chelator approved for the treatment of chronic iron overload due to blood transfusions [9-13]. The EPIC (Evaluation of Patients' Iron Chelation with Exjade $^{\mathrm{TM}}$ ) study indicated that the overall median serum ferritin level decreased significantly with deferasirox administration, both in chelation-naïve patients and those previously receiving chelation treatment [10]. The current treatment guidelines, based on these clinical studies and expert consensus, recommends chelation therapy for transfusion-dependent patients with serum ferritin levels $>1000 \mathrm{ng} / \mathrm{mL}$, depending on the transfusion rate [14-16]. In Japan, deferasirox was approved 
about two years ago, and data such as efficacy and tolerability have accumulated; however, there have been few publications regarding its use in clinical practice. In this retrospective study, we share our 2-year experience of deferasirox regarding clinical outcomes including adverse events (AEs).

\section{Methods}

Deferasirox was given to 18 hematological disorder patients with serum ferritin levels of $>1000 \mathrm{ng} / \mathrm{mL}$ due to frequent RBC transfusion. The starting dose was individualized according to blood transfusion frequency or age. Routine clinical laboratory data regarding CBC, liver, renal, and other functions were followed, and serum ferritin was assessed every 4 weeks. Efficacy was evaluated as a change in the serum ferritin level and clinical indicators (frequency of transfusion, skin pigmentation, liver function, cardiac function, glycoalbumin, etc., according to the organ damage in each patient). Safety was evaluated by monitoring of laboratory data and a medical physical exam. Dose adjustment was performed according to the physician's discretion based on each patient's clinical indicators. In the present study, there were no patients in whom the serum ferritin values fell to less than $500 \mathrm{ng} / \mathrm{mL}$ during the clinical course.

All patients had received previous DFO administration for iron chelation, but had not experienced success with it. In Japan, subcutaneous DFO injection is not permitted, and it is difficult to use intravenous infection every day for chelation. Instead, the patients in this study were given DFO in every transfusion, but the cumulative effect of the transfusions had outweighed its effect, resulting in gradually increased serum ferritin. AEs were graded according to the National Cancer Institute Common Toxicity Criteria (version 3). The interaction between total RBC transfusion units and serum ferritin level in all patients was calculated by the Pearson product-moment correlation coefficient using JMP software (Tokyo, Japan). The data of basal serum ferritin was collected just before deferasirox induction. Changes in serum ferritin levels and overall clinical improvement were analyzed in the 10 patients who could sustain deferasirox administration for at least 6 months.

\section{Results}

\subsection{Patient Characteristics}

Data from 18 patients who received deferasirox at our institution were collected (Table 1). The sex ratio was 11:7 (male:female), and the median age at deferasirox initiation was 67 years (range: $44-82$ years). The underlying diseases in patients were MDS $(n=10)$, AA ( $n$ $=4$ ), myeloproliferative neoplasm (MPN; $n=3$ ) and pure red cell aplasia $(n=1)$. The subtypes of MDS were refractory anemia (RA; $n=5)$, refractory anemia with excess blast (RAEB; $n=4$ ), and refractory anemia with ring sideroblasts (RARS; $n=1$ ). The median duration from diagnosis to deferasirox induction was 3.9 years (range: 0.7 - 17.7 years). The average total RBC transfusion already received before deferasirox initiation was

Table 1. Patients' characteristics.

\begin{tabular}{|c|c|c|c|c|c|c|c|c|}
\hline No & Age & Sex & Diagnosis $^{* 1}$ & $\begin{array}{l}\text { Disease } \\
\text { duratiion } \\
\text { (years) }^{* 2}\end{array}$ & $\begin{array}{l}\text { Total } \\
\text { T/F dose } \\
\text { (Units) }^{* 3}\end{array}$ & $\begin{array}{l}\text { Serum Ferritin } \\
(\mathrm{ng} / \mathrm{dl})^{* 4}\end{array}$ & $\begin{array}{l}\mathrm{T} / \mathrm{F} \\
\text { require- } \\
\text { ment }^{* 5}\end{array}$ & Complication $^{* 6}$ \\
\hline 1 & 74 & Female & AA & 3.4 & 170 & 6425 & 5 & Skin, Herat \\
\hline 2 & 79 & Female & MDS(RA) & 1.7 & 84 & 1806 & 4 & Skin \\
\hline 3 & 65 & Female & MDS(RA) & 2 & 60 & 1105 & 5 & - \\
\hline 4 & 61 & Male & MDS(RARS) & 5.6 & 146 & 4838 & 6 & - \\
\hline 5 & 61 & Female & AA & 0.7 & 66 & 1811 & 8 & - \\
\hline 6 & 44 & Male & MDS(RA) & 2 & 18 & 1247 & 2 & - \\
\hline 7 & 82 & Female & MPN & 4 & 191 & 6693 & 6 & - \\
\hline 8 & 61 & Male & MDS(RAEB) & 5.1 & 130 & 2561 & 9 & Skin, Herat \\
\hline 9 & 69 & Male & AA & 10.5 & 160 & 9423 & 6 & Skin, Herat, DM, Liver \\
\hline 10 & 67 & Male & MPN & 2.2 & 180 & 1440 & 14 & Skin \\
\hline 11 & 67 & Female & AA & 2.2 & 132 & 2327 & 4 & Skin \\
\hline 12 & 67 & Female & MDS(RA) & 3.4 & 102 & 2645 & 4 & - \\
\hline 13 & 72 & Male & MDS(RAEB) & 1 & 44 & 1265 & 7 & - \\
\hline 14 & 71 & Male & PRCA & 2.8 & 84 & 3980 & 6 & - \\
\hline 15 & 63 & Male & MPN & 17.7 & 206 & 1563 & 4 & - \\
\hline 16 & 69 & Male & MDS(RAEB) & 3.3 & 132 & 3328 & 6 & - \\
\hline 17 & 75 & Male & MDS(RAEB) & 1.8 & 116 & 2612 & 8 & - \\
\hline 18 & 60 & Male & MDS(RA) & 1 & 20 & 1851 & 6 & - \\
\hline Mean & 67 & & & 3.9 & 113.8 & 3162 & 6.1 & \\
\hline
\end{tabular}

*1. AA, aplastic anemia; MDS, myelodysplastic syndrome; RA, refractory anemia; RARS, refractory anemia with ring sideroblasts; MPN, myeloproliferative neoplasm; RAEB, refractory anemia with excess blasts; PRCA, pure red cell aplasia. *2. Duration from diagnosis to the time of deferasirox induction. *3. Total recieving $\mathrm{RBC}$ dose until deferasirox. 
113.8 units (range: 18 - 206 units). The average serum ferritin level was $3162 \mathrm{ng} / \mathrm{ml}$ (range: 1105 - 9423). The average number of units of RBC transfusion per month was 6.1 (range: 2 - 14). The complications assumedly due to transfusion-induced iron overload were skin pigmentation $(n=1)$, skin pigmentation and heart failure $(n$ $=2$ ), and skin pigmentation, heart failure, diabetes mellitus and liver dysfunction $(n=1)$. Statistical analysis revealed a positive relationship between RBC total transfusion units and serum ferritin level in 18 patients $(r=0.85$ in Figure 1).

\subsection{Deferasirox Administration}

The initial and maintenance doses, as well as any dose modifications, were determined according to the physician's discretion, considering renal function, frequency of transfusion, and serum ferritin level. The details of deferasirox administration in each patient are shown in Table 2. The average initiated deferasirox dose was 11.8 $\mathrm{mg} / \mathrm{kg}$ (range: 6.4 - 26.3). The median duration of deferasirox usage was 10.8 months (range: 0.2 - 24.5). There were 10 patients who sustained treatment for over 6 months; in this group, the average maintenance dose was $10.8 \mathrm{mg} / \mathrm{kg} /$ day (range; $6.4-17.9$ ). Thirteen of 18 patients finally ceased deferasirox administration, and 5 patients were still receiving deferasirox at the latest observed time point. The changes of serum ferritin in the 10 patients who could continue at least 6 months are

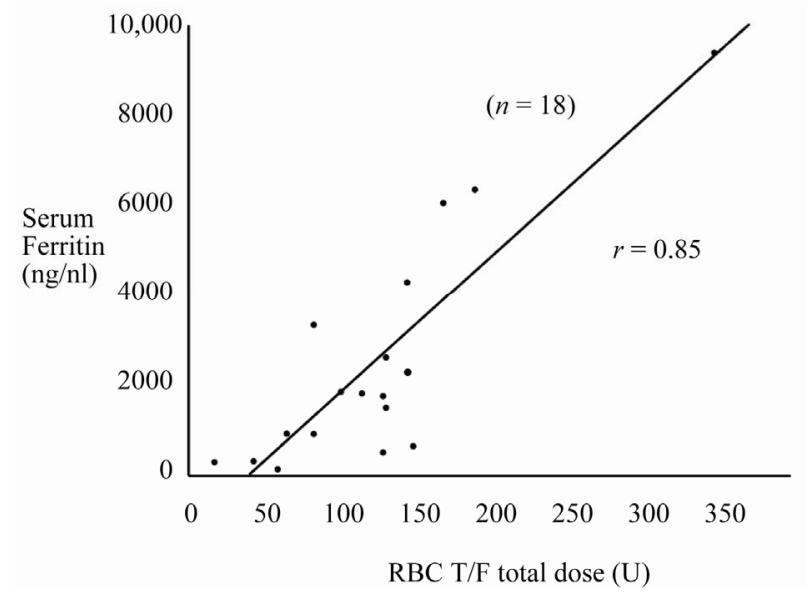

Figure 1. Relationship between total transfusion and serum ferritin level at start of deferasirox. A significant correlation between total transfusion units and serum ferritin level was demonstrated $(r=0.85)$.

displayed in Figure 2. Serum ferritin reduction more than $1000 \mathrm{ng} / \mathrm{ml}$ was achieved in 4 patients, and 2 patients had decreases over $3000 \mathrm{ng} / \mathrm{ml}$. Only 1 patient showed a marked increase in serum ferritin levels after deferasirox administration; the serum ferritin level in the other 3 patients was stable. The reasons for discontinuation were infection $(n=6)$, skin rash $(n=3)$, nausea $(n$ $=2)$, thrombocytopenia $(n=1)$, and fatigue with dry mouth $(n=1)$, respectively (Table 2$)$. Sixteen of 18

Table 2. Clinical course.

\begin{tabular}{|c|c|c|c|c|c|c|c|c|}
\hline No & $\begin{array}{l}\text { Initial } \\
\text { dose } \\
(\mathrm{mg} / \mathrm{Kg})\end{array}$ & $\begin{array}{l}\text { Duration }{ }^{* 1} \\
\text { (Month) }\end{array}$ & $\begin{array}{l}\text { Maintenance } \\
\text { dose }^{* 2} \\
(\mathrm{mg} / \mathrm{Kg})\end{array}$ & Continuation & $\begin{array}{l}\text { Reason of } \\
\text { Discontinuation }{ }^{* 3} \\
\text { (grade) }\end{array}$ & $\begin{array}{l}\text { Other Adverse } \\
\text { Events (grade) }\end{array}$ & Outcome & $\begin{array}{l}\text { Clinical } \\
\text { Improvements }^{* 4}\end{array}$ \\
\hline 1 & 12.8 & 14.2 & 12.8 & - & Infection (4) & - & Dead & T/F requirement, Skin \\
\hline 3 & 10.2 & 1.6 & - & - & Infection (3) & - & Alive & - \\
\hline 4 & 9.1 & 1.7 & - & - & Fatigue (2) & Dry Mouth (2) & Dead & - \\
\hline 5 & 9.6 & 11.2 & 9.6 & - & Nausea (2) & - & Alive & - \\
\hline 6 & 6.7 & 0.7 & - & - & Skin Rash (2) & - & Alive & - \\
\hline 7 & 9.9 & 11.7 & 9.9 & - & Nausea (2) & - & Alive & - \\
\hline 8 & 8.9 & 0.8 & - & - & Skin Rash (2) & - & Dead & - \\
\hline 9 & 17.9 & 24.5 & 17.9 & + & - & $\begin{array}{l}\text { Diarrhea(2), Renal } \\
\text { dysfunction (2) }\end{array}$ & Alive & $\begin{array}{l}\text { Skin, Heart, DM, } \\
\text { Liver }\end{array}$ \\
\hline 10 & 20.4 & 3.8 & - & - & Infection (4) & - & Dead & - \\
\hline 11 & 18.2 & 24.3 & 9.1 & + & - & $\begin{array}{l}\text { Renal } \\
\text { Dysfunction(2) }\end{array}$ & Alive & Skin \\
\hline 12 & 26.3 & 23.2 & 13.2 & + & - & - & Alive & Skin \\
\hline 13 & 9.6 & 7.8 & 9.6 & - & Infection (5) & - & Dead & - \\
\hline 14 & 7.7 & 2.1 & - & - & Thrombocytopenia (2) & - & Alive & - \\
\hline 15 & 8.6 & 17.8 & 8.6 & + & - & Renal Dysfunction(2) & Alive & - \\
\hline 16 & 10.6 & 4.7 & - & - & Infection (4) & - & Dead & - \\
\hline 17 & 8.1 & 11.3 & 10.6 & - & Infection (5) & - & Dead & - \\
\hline 18 & 6.4 & 7.2 & 6.4 & + & - & - & Alive & - \\
\hline
\end{tabular}

*1. Duration of deferasirox administration. *2. Indicated the data of patients with recieving deferasirox over 6 months. *3. According to NCNI version 3 . *4. At the time of the final confirmed date. T/F, transfusion; skin, Skin pigmentation; Herat, chronic hear failure; DM, diabetes mellitus; Liver, liver dysfunction. 


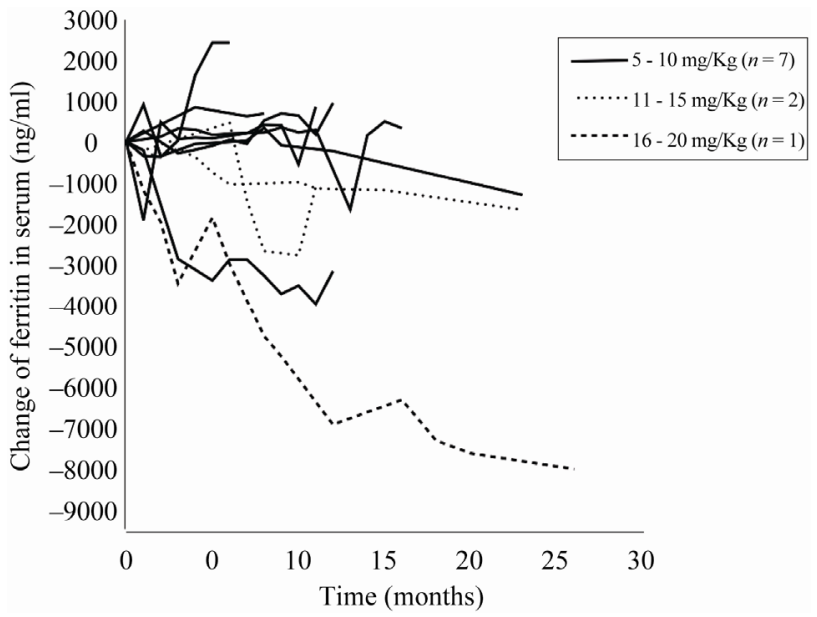

Figure 2. Change of serum ferritin level under deferasirox administration. Changes of serum ferritin in 10 patients who could sustain at least 6 months of treatment are displayed. The solid line shows the 5 - $10 \mathrm{mg} / \mathrm{kg}$ administration group ( $n=7)$; dotted line, $11-15 \mathrm{mg} / \mathrm{kg}(n=2)$, and bold dotted line, 16 - $20 \mathrm{mg} / \mathrm{kg}(n=1)$. Serum ferritin reduction more than $1000 \mathrm{ng} / \mathrm{ml}$ was found in 4 patients, and 2 patients had over $3000 \mathrm{ng} / \mathrm{ml}$ decrease (patient 7 and 9). Only one patient showed serum ferritin elevation under deferasirox administration (patient 16). pt, patient. patients (89\%) had AEs; all events other than infections were less than grade 3 . All infections that appeared in 6 patients were grade 3 or higher. Four of 6 patients were MDS (3 was RAEB, and 1 was RA). Renal dysfunction developed in 3 patients, two of whom were simultaneously receiving cyclosporin A (CyA). Improvement of renal dysfunction was observed in these after withdrawal of CyA.

Clinical benefits were documented in 4 patients. Patient 1 showed both reduction of transfusion frequency and improvement of skin pigmentation, and 2 patients (patient 11 and 12) showed improvement of skin pigmentation. Patient 9 showed improvement of skin pigmentation, chronic heart failure, diabetes mellitus, and liver dysfunction, as described later. All 4 took deferasirox for at least 6 months. Although dose escalation was attempted in 5 patients, 4 of these attempts failed because of AEs such as diarrhea, appetite loss, and renal dysfunction (data not shown).

\subsection{Case Presentation}

Figure 3 shows a remarkably treatment-responsive 69-year-old male patient with AA, having skin pigmenserum glycoalbumin, cardiac function, and skin pig-

Patient 9: 69 year-old-male with severe type-aplastic anemia

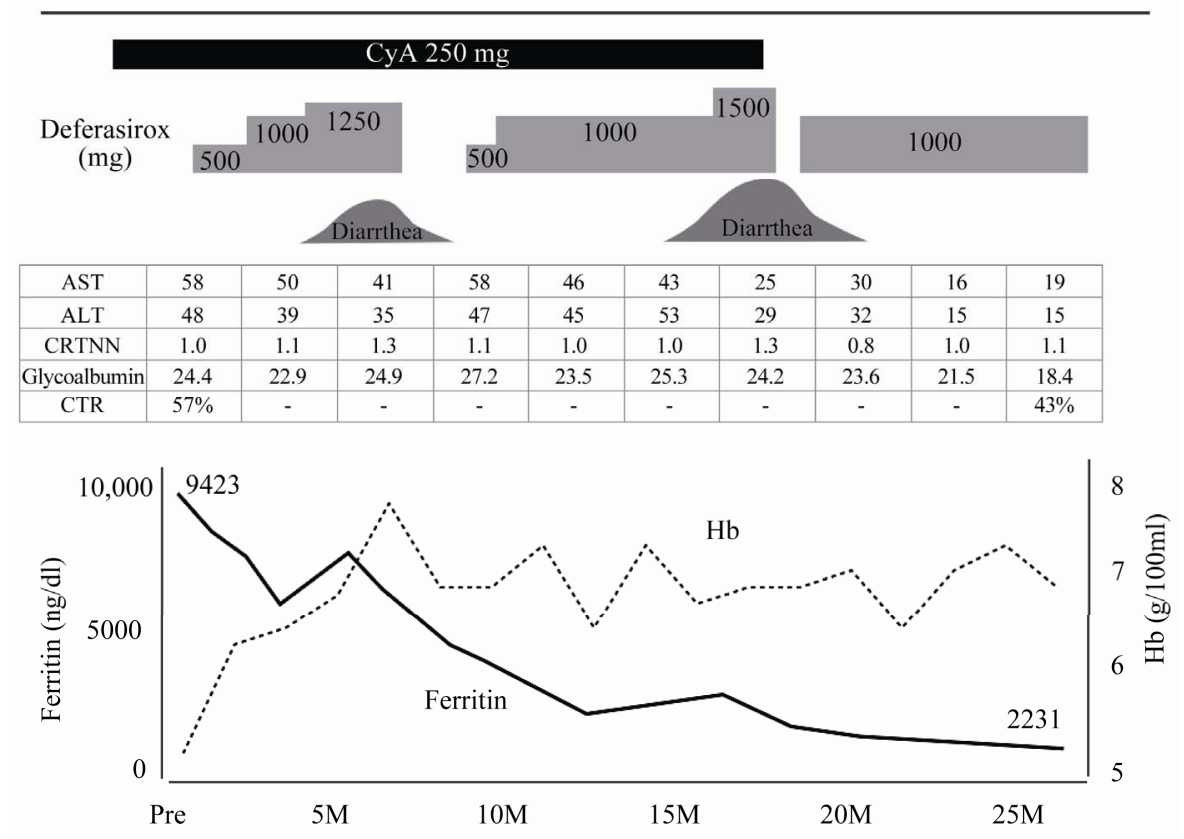

Figure 3. Case presentation. A 69-year-old male patient with severe-type AA, having skin pigmentation, diabetes mellitus, liver dysfunction and chronic heart failure due to iron overload was administered deferasirox. The serum ferritin level at the induction of deferasirox was $9423 \mathrm{ng} / \mathrm{ml}$. The administration of deferasirox had remarkably beneficial effects such as the improvement of liver function, serum glycoalbumin, cardiac function, and skin pigmentation in addition to decreasing the serum ferritin level to $2231 \mathrm{ng} / \mathrm{ml}$. Attempts to escalate the dose of deferasirox failed due to diarrhea, resulting in a 1000 -mg maintenance dose. The solid line shows the change of serum ferritin, and the dotted line shows the change hemoglobin (Hb). AST, aspartate aminotransferase; ALT, alanine aminotransferase; CRTNN, creatinine; CTR, cardio-thoracic ratio. 
mentation in addition to decreasing the serum ferritin level to $2231 \mathrm{ng} / \mathrm{ml}$. Dose escalation was attempted two times, but 1250 or $1500 \mathrm{mg} /$ day administration failed, tation, diabetes mellitus, liver dysfunction and chronic heart failure due to iron overload. His serum ferritin level at the induction of deferasirox was $9423 \mathrm{ng} / \mathrm{ml}$, and the administration of deferasirox had numerous beneficial effects such as the improvement of liver function, and the maintenance dose was defined as $1000 \mathrm{mg}$ (17.9 $\mathrm{mg} / \mathrm{kg}$ ). Though the frequency of transfusion was not changed, the hemoglobin was gradually elevated from its baseline value, showing the effectiveness of deferasirox. CyA was not effective and renal impairment was found, so that CyA had to be eventually stopped. Liver dysfunction, renal impairment, and diabetes mellitus were improved as indicated in Figure 3. Although he had a chronic heart failure leading to a wide cardiothoracic ratio (CTR), deferasirox administration seemed to ameliorate the CTR, from $57 \%$ to $43 \%$.

\section{Discussion}

Deferasirox, a once-daily oral iron chelator, has been demonstrated in various studies worldwide involving large numbers of patients with a variety of transfusion-dependent anemias, with similar efficacy to DFO at comparable doses. A phase I and extended study in Japan was developed with similar potential efficacy and safety as those seen in several western clinical trials [17]. However, there have been few publications regarding the outcome of its usage in clinical practice in Japan. To discuss this point, we collected and analyzed data from 18 patients who have been treated with deferasirox at our institution.

In this retrospective study, there were several important findings regarding the usage of deferasirox in clinical practice. First, this study showed that lower doses $(<20 \mathrm{mg} / \mathrm{kg})$ had some extent of clinical efficacy. Previous clinical trials have clearly demonstrated the dose-dependent iron-chelation effects of deferasirox administration, and have implied that at least $20 \mathrm{mg} / \mathrm{kg}$ is required for efficacy [18]. It was hard to evaluate this effect because there were no patients in the present study who could tolerate a dose greater than $20 \mathrm{mg} / \mathrm{kg}$; however, 4 patients who received a dose lower than $20 \mathrm{mg} / \mathrm{kg}$ showed decreased serum ferritin levels. In particular, the ferritin reductions in 2 patients (patient 7 and 9, receiving $9.9 \mathrm{mg} / \mathrm{kg}$ and $17.9 \mathrm{mg} / \mathrm{kg}$, respectively) were more than $3000 \mathrm{ng} / \mathrm{ml}$ as shown in Figure 2. Considering that these patients receive 6 units of RBC transfusion per month, deferasirox achieved sustained iron chelation even at lower-than-recommended doses. The clinical course of the latter patient was remarkable (Figure 3), showing improvement of multiple organs with iron chelation, and $7000 \mathrm{ng} / \mathrm{dl}$ serum ferritin reduction.

Second, the maintenance dose of deferasirox in 10 patients who sustained at least 6 months of treatment was $10.8 \mathrm{mg} / \mathrm{kg}$ on average, less than those of the previously reported clinical studies. The 1-year EPIC study enrolled 1744 patients with transfusion-dependent anemias, of whom $79.6 \%$ completed 1 year of treatment; over $90 \%$ of these took doses more than $20 \mathrm{mg} / \mathrm{kg}$ [19]. In this study, we tried with 4 patients to escalate the deferasirox dose over $20 \mathrm{mg} / \mathrm{kg}$, but these escalations failed due to AEs; for some reason, it was difficult to maintain the recommenced deferasirox dose in this study. The phase I clinical study of deferasirox on Japanese patients with transfusion-dependent anemias indicated that the pharmacokinetics-dose relationship was similar in Japanese and Caucasians [17]; hence, this phenomenon was not likely due to race.

Third, the discontinuation rate (72\%: 13 of 18 patients) was higher than those of previous studies. For instance, the phase I and extended study in Japan had a discontinuation rate of only 19\% (4 of 21 patients) [17]. To understand this discrepancy, it is important to focus on the underlying disease. The EPIC study demonstrated that the incidence of AEs and discontinuation in MDS patient groups was higher than those in other anemia patient groups [19], and this study included 10 MDS patients (55\%), of whom 8 ultimately discontinued the medication because of AEs. In addition, with regard to subtypes of MDS, 2 of 5 MDS-RA patients could sustain deferasirox administration at the time of writing, and improvement of skin pigmentation and the reduction of serum ferritin was observed in patient 12; however, all 4 MDS-RAEB patients interrupted the medication because of AEs. Moreover, 3 of them developed severe infections, resulting in fatality in 2 patients. Our data confirmed current consensus-driven guidelines in deferasirox usage, recommending deferasirox usage for low-risk MDS patients, not for high-risk groups such as RAEB or leukemic patients [20]. Meanwhile, it was surprising that the leading AE type in this study was infection, and that all of them were severe, i.e., grade 3 or more. It has been suggested that iron chelation therapies enhance immunity against infections, based on the fact that iron overload promotes free radical tissue damage and organ failure, undermines immune protection and facilitates pathogen invasion [21]. On the contrary, DFO, an iron chelator, is also a siderophore, which binds iron and transports it into microorganisms to help maintain their activity and grow, and thus exacerbates infections in various immunosuppressive settings [22]. Indeed, 46 of 59 dialysis patients who received DFO developed mu- 
cormycosis [23]. Of 1774 patients receiving deferasirox in the EPIC study, serious pyrexia ( $n=51 ; 2.9 \%)$, pneumonia ( $n=23 ; 1.3 \%)$, and sepsis $(n=20 ; 1.1 \%)$ were observed [17]. Furthermore, 26 deaths occurred in 341 MDS patients including 3 cases of septic shock [18]. Although deferasirox is not a siderophore so it is not clear-cut whether deferasirox might impair immunity against bacteria and fungus as DFO does, the results of the present study cannot rule out the possibility that deferasirox impairs immunity, given the fact that 2 nonMDS anemias developed (patient 1-AA and patient 9-MPN). Further clinical investigation and analysis of this issue will be required.

In summary, the potential for beneficial iron chelation of deferasirox was demonstrated in patients receiving less than recommended $20-\mathrm{mg} / \mathrm{kg}$ dose in clinical practice. On the other hand, deferasirox did not show clinical efficacy in high-risk MDS such as RAEB, as in other recent clinical studies. Poor tolerability was indicated by AEs, especially infections, 2 of which became fatal. Considering the fact that 2 non-MDS patients developed severe infection in this study, the possibility of deferasirox-mediated impaired immunity cannot be ruled out. As this was a small study, further investigations in clinical practice are very important to analyze strategies focusing on the real efficacy of deferasirox among transfusion-dependent anemia patients, including ways of addressing the infection issue.

\section{REFERENCES}

[1] N. C. Andrews, "Disorders of Iron Metabolism," The New England Journal of Medicine, Vol. 341, 1999, pp. 1986-1995. doi:10.1056/NEJM199912233412607

[2] J. P. Kushner, J. P. Porter and N. F. Olivieri, "Secondary Iron Overload," The American Society of Hematology Education Program Book, Vol. 1, 2001, pp. 47-61. doi:10.1182/asheducation-2001.1.47

[3] M. Takatoku, T. Uchiyama, S. Okamoto, Y. Kanakura, et al., "Retrospective Nationwide Survey of Japanese Patients with Transfusion-Dependent MDS and Aplastic Anemia Highlights the Negative Impact of Iron Overload on Morbidity/Mortality,” European Journal of Haematology, Vol. 78, No. 6, 2007, pp. 487-494. doi:10.1111/j.1600-0609.2007.00842.X

[4] A. Shander and K. Sazama, "Clinical Consequences of Iron Overload from Chronic Red Blood Cell Transfusions, Its Diagnosis, and Its Management by Chelation Therapy,” Transfusion, Vol. 50, No. 5, 2010, pp. 1144-1155. doi:10.1111/j.1537-2995.2009.02551.x

[5] L. Malcovati, "Impact of Transfusion Dependency and Secondary Iron Overload on the Survival of Patients with Myelodysplastic Syndromes," Leukemia Research, Vol. 31, No. S3, 2007, pp. S2-S6.

\section{doi:10.1016/S0145-2126(07)70459-9}

[6] E. N. Oliva, F. Ronco, A. Marino, C. Alati, G. Praticò and F. Nobile, "Iron Chelation Therapy Associated with Improvement of Hematopoiesis in Transfusion-Dependent Patients," Transfusion, Vol. 50, No. 7, 2010, pp. 15681570. doi:10.1111/j.1537-2995.2010.02617.x

[7] P. J. Giardina and R. W. Grady, "Chelation Therapy in Beta-Thalassemia: The Benefits and Limitations of Desferrioxamine,” Seminars in Hematology, Vol. 32, No. 4, 1995, pp. 304-312.

[8] V. Gabutti and A. Piga, "Results of Long-Term IronChelating Therapy,” Acta Haematologica, Vol. 95, No. 1, 1996, pp. 26-36. doi:10.1159/000203853

[9] M. D. Cappellini, A. Cohen, A. Piga, M. Bejaoui, et al., "A Phase 3 Study of Deferasirox (ICL670), a Once-Daily Oral Iron Chelator, in Patients with $\beta$-Thalassemia," Blood, Vol. 107, No. 9, 2006, pp. 3455-3462. doi:10.1182/blood-2005-08-3430

[10] J. Porter, R. Galanello, G. Saglio, E. J. Neufeld, et al., "Relative Response of Patients with Myelodysplastic Syndromes and Other Transfusion-Dependent Anaemias to Deferasirox (ICL670): A 1-yr Prospective Study,” European Journal of Haematology, Vol. 80, No. 2, 2008, pp. 168-176. doi:10.1111/j.1600-0609.2007.00985.X

[11] N. Gattermann, C. Finelli, M. D. Porta, P. Fenaux, A. Ganser, A. Guerci-Bresler, M. Schmid, K. Taylor, D. Vassilieff, D. Habr, G. Domokos, B. Roubert and C. Rose, "Deferasirox in Iron-Overloaded Patients with Transfusion-Dependent Myelodysplastic Syndromes: Results from the Large 1-Year EPIC Study,” Leukemia Research, Vol. 34, No. 9, 2010, pp. 1143-1150. doi:10.1016/j.leukres.2010.03.009

[12] F. Wimazal, T. Nosslinger, C. Baumgartner, W. R. Sperr, M. Pfeilstocker and P. Valent, "Deferasirox Induces Regression of Iron Overload in Patients with Myelodysplastic Syndromes,” European Journal of Clinical Investigation, Vol. 39, No. 5, 2009, pp. 406-411. doi:10.1111/j.1365-2362.2009.02108.x

[13] D. Chirnomas, A. L. Smith, J. Braunstein, Y. Finkelstein, L. Pereira, A. K. Bergmann, F. D. Grant, C. Paley, M. Shannon and E. J. Neufeld, "Deferasirox Pharmacokinetics in Patients with Adequate versus Inadequate Response,” Blood, Vol. 114, No. 19, 2009, pp. 4009-4013. doi:10.1182/blood-2009-05-222729

[14] J. M. Bennett, “Consensus Statement on Iron Overload in Myelodysplastic Syndromes,” American Journal of Hematology, Vol. 83, No. 11, 2008, pp. 858-861. doi:10.1002/ajh.21269

[15] T. Suzuki, M. Tomonaga, Y. Miyazaki, S. Nakao, K. Ohyashiki, I. Matsumura, Y. Kohgo, Y. Niitsu, S. Kojima and K. Ozawa, "Japanese Epidemiological Survey with Consensus Statement on Japanese Guidelines for Treatment of Iron Overload in Bone Marrow Failure Syndromes,” International Journal of Hematology, Vol. 88, No. 1, 2008, pp. 30-35. doi:10.1007/s12185-008-0119-y 
[16] National Comprehensive Cancer Network (NCCN) Clinical Practice Guidelines in Oncology Version 1, "Myelodysplastic Syndromes; 2009,” 2009.

http://www.nccn.org/professionals/physician gls/pdf/mds.pdf.

[17] K. Miyazawa, K. Ohyashiki, A. Urabe, T. Hata, S. Nakao, K. Ozawa, T. Ishikawa, J. Kato, Y. Tatsumi, H. Mori, M. Kondo, J. Taniguchi, H. Tanii, L. Rojkjaer and M. Omine, "A Safety, Pharmacokinetic and Pharmacodynamic Investigation of Deferasirox (Exjade, ICL670) in Patients with Transfusion-Dependent Anemias and Iron-Overload: A Phase I Study in Japan,” International Journal of Hematology, Vol. 88, No. 1, 2008, pp. 73-81. doi:10.1007/s12185-008-0115-2

[18] A. Taher, A. El-Beshlawy, M. S. Elalfy, K. Al Zir, S. Daar, D. Habr, U. Kriemler-Krahn, A. Hmissi and A. Al Jefri, "Efficacy and Safety of Deferasirox, an Oral Iron Chelator, in Heavily Iron-Overloaded Patients with Beta-Thalassaemia: The ESCALATOR Study,” European Journal of Haematology, Vol. 82, No. 6, 2009, pp. 458-465. doi:10.1111/j.1600-0609.2009.01228.x

[19] M. D. Cappellini, J. Porter, A. El-Beshlawy, C. K. Li, J. F. Seymour, M. Elalfy, N. Gattermann, S. Giraudier, J. W. Lee, L. L. Chan, K. H. Lin, C. Rose, A. Taher, S. L. Thein, V. Viprakasit, D. Habr, G. Domokos, B. Roubert and A. Kattamis, "Tailoring Iron Chelation by Iron Intake and
Serum Ferritin: The Prospective EPIC Study of Deferasirox in 1744 Patients with Transfusion-Dependent Anemias,” Haematologica, Vol. 95, No. 4, 2010, pp. 557-566. doi:10.3324/haematol.2009.014696

[20] J. M. Bennett, "Consensus Statement on Iron Overload in Myelodysplastic Syndromes,” American Journal of Hematology, Vol. 83, No. 11, 2008, pp. 858-861. doi:10.1002/ajh.21269

[21] J. R. Boelaert, J. Van Cutsem, M. de Locht, Y. J. Schneider and R. R. Crichton, "Deferoxamine Augments Growth and Pathogenicity of Rhizopus, While Hydroxypyridinone Chelators Have No Effect," Kidney International, Vol. 45, No. 45, 1994, pp. 667-671. doi:10.1038/ki.1994.89

[22] H. Keberle, "The Biochemistry of Desferrioxamine and Its Relation to Iron Metabolism," Annals of the New York Academy of Sciences, Vol. 119, 1964, pp. 758-768. doi:10.1111/j.1749-6632.1965.tb54077.x

[23] J. R. Boelaert, M. de Locht, J. Van Cutsem, V. Kerrels, B. Cantinieaux, A. Verdonck, H. W. Van Landuyt and Y. J. Schneider, "Mucormycosis during Deferoxamine Therapy is a Siderophore-Mediated Infection. in vitro and in vivo Animal Studies," The Journal of Clinical Investigation, Vol. 91, No. 5, 1993, pp. 1979-1986. doi:10.1172/JCI116419 